\title{
Musical Transcendence: A Jazz Musician's Journey into the Heart of Indian Classical Music
}

\author{
Jonathan Kay
}

\section{Introduction}

How do musical improvisers find their direction in the vast world of sonic expression? There is an endless array of colourful vibrations set out on an infinite palette: notes, phrases, scales, modes, chords, sounds, squawks, and squeaks, all at our fingertips to explore and create with. From 1999-2003, as a young saxophone student of Jazz Studies at Humber College in Toronto, I was constantly inspired and overwhelmed by the cosmic scope of jazz and creative improvisation. Under the mentorship of Pat LaBarbera, among many other teachers, I immersed myself in the music and traditions of the great jazz masters.

After college, as one of Toronto's up-and-coming young jazz musicians, an in-demand sideman and bandleader, there was a constant phrase reverberating in my head, words of wisdom passed on to me by almost all of my mentors: "find your own voice." I was playing music every day, sometimes with greater and far more established musicians-and I was even making a modest living — but at the end of every day, I would come home and wonder, "What is it that I want to express through music? What music most deeply resonates with me? Who am I?"

Contemplating these questions forced me to evolve past mimicking the "sounds" of great musicians, or playing the "bag" as demanded by a professional gig. I started to explore deeper into recesses of my creative being that were yearning for discovery and expression, a scary process at first, but a necessary one that began my transformation into an artist.

In searching for an inner musical voice, my curiosity grew beyond jazz standards to energy-based modal music, leading me deep into the sounds of Ornette Coleman and John Coltrane's later work: another universe of boundless, creative expression.

Notwithstanding my vivid experiences playing these freer forms of jazz, I still found their subtle boundaries of genre and motif an incomplete representation of who I was. My search for purpose, meaning, and reason pushed far beyond my current conception of what it meant to be an artist. I began exploring Indian philosophy and spirituality and found that this ancient wisdom answered many of my questions and affirmed much of what I already believed.

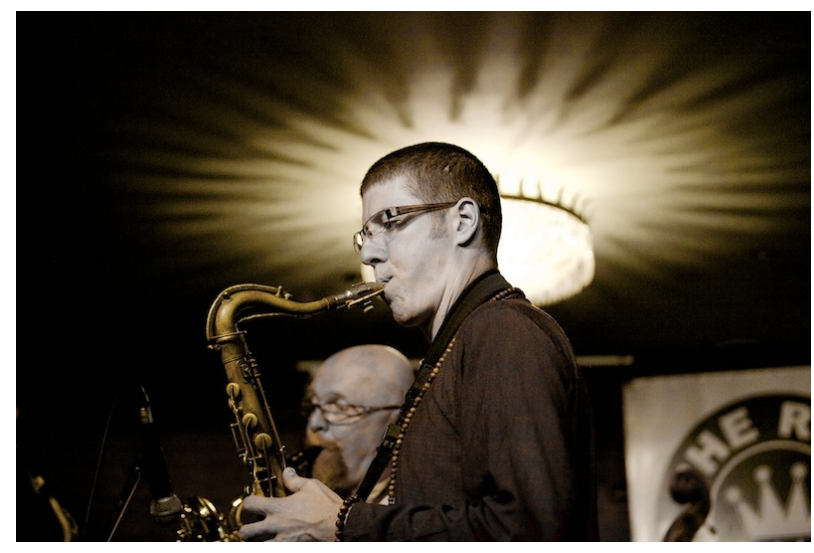

I became fascinated with Indian culture and soon thereafter started listening to the maestros of India's Shastriya Sangeet ${ }^{1}$ (instrumentalists Ali Akbar Khan, Ravi Shankar, Annapurna Devi, Bismillah Khan, Pannalal Ghosh, Vilayat Khan, and Nikhil Banerjee; and vocalists Bade Ghulam Ali Khan and Amir Khan). The spirit that emanated from the ragas when masterfully performed by these Indian maestros prompted me to look inward to a place music had never taken me before: a place of tranquility, peace, and meditation. Raga music is as poignant as the cosmic philosophy and mystical religions born in India, and to me this exotic and penetrating music seemed to be vibrating from a deep spiritual source of sublime beauty and universal joy. ${ }^{2}$

During that year, I often found myself seated on the floor of my practice room with my electric tanpura box (a device that emulates the acoustic tanpura, a four-stringed drone instrument that creates the tonal canvas on which Indian ragas are set). I had also fallen in love with the sound of India's bamboo flute, the bansuri, and once finding one in a local Indian marketplace, I started practicing whatever basics I could find from books and videos. At times, this exotic instrument almost made me forget my beloved saxophone, but naturally I also began experimenting by improvising along with the tanpura on the saxophone, and that gave rise to a world of inspiring possibilities. I found there to be a natural bridge between jazz improvisation and Indian music.

Toronto based tabla player Ravi Naimpally, who I met as a professor of world music at Humber College, nurtured this dialogue by sharing his own journey from Indian music to jazz. Inviting me to sit with his Indo-Jazz band, Tasa, I felt 
so inspired to be playing music with like-minded people and could feel the level of their musicianship pull me up to new heights. Spending time with Ravi and his music-loving family, listening to ragas and hearing stories about the maestros, was such an important introduction to the vast and rich tradition of Indian musical culture.

As my motivation to explore the exotic world of the ragas grew, I knew that I needed to hear Indian Classical music at the feet of a maestro to truly understand what this music meant to me. Immersed alongside me in this exploration was my younger brother, alto-saxophonist Andrew Kay, and our classmate and friend, bassist Justin Gray: we made our first pilgrimage to Kolkata for a five-week study trip in May 2006.

This trip would further a deep bond between the three of us, and to this day we continue to work intimately together developing the music that we began during that trip. Currently, The Monsoon Trio is the first ensemble to collectively study in the traditional Guru-Shishya Parampara system and perform the vocal and instrumental styles of North Indian Classical music on modern western instruments. Justin Gray plays bass veena, ${ }^{3}$

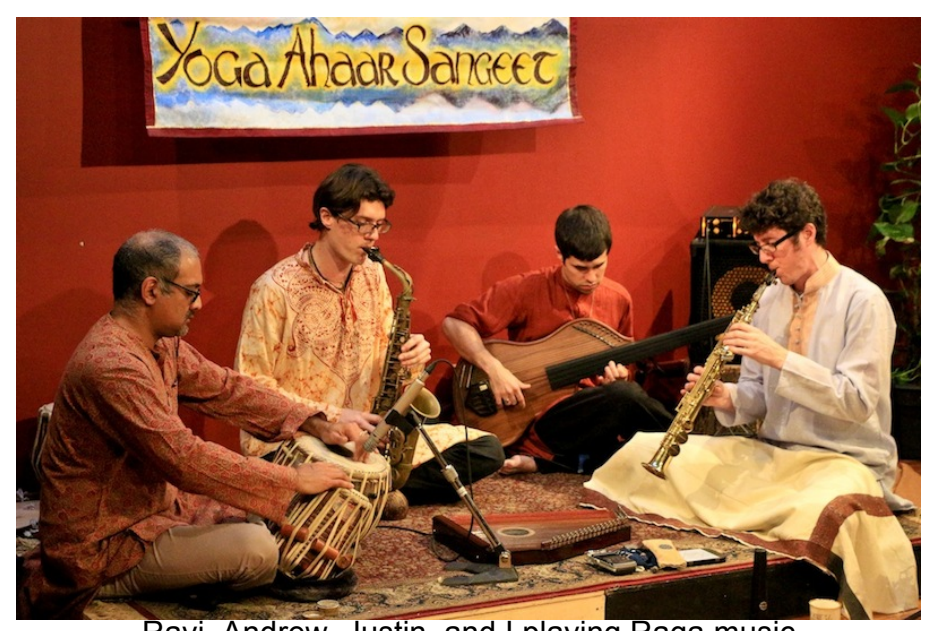

Ravi, Andrew, Justin, and I playing Raga music

Andrew Kay plays alto saxophone, and I play soprano and tenor saxophones. Our first album (Pranaam, recorded on September 12-14th, 2014) was produced by our Guru, Pandit Shantanu Bhattacharyya, and features Subhajyoti Guha, one of India's best younger-generation tabla players. Below are some clips from this recording:

- $\quad$ Raga Bhairav is an early morning Raga that is to be played just as the sun is coming over the horizon. It is an ancient raga that is deeply meditative and devotional in nature. This recording features melodies composed specially for this project by our Guru.

\section{Click here to listen to audio: Raga Bhairav}

- $\quad$ Raga Jaijaiwanti is an evening Raga that has a romantic mood. It is set in the Monsoon season and its traditional bandishes (songs) depict this vibrantly and colourfully in the Indian countryside.

Click here to listen to audio: Raga Jaijaiwanti

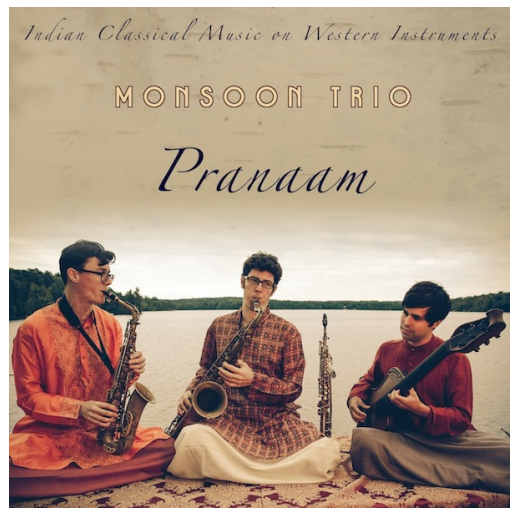

\section{Part One: Cultural Assimilation}

\section{Journey to Kolkata, India}

My very first day in Kolkata was an overwhelming shock that awakened me to a profoundly different culture and way of life. The very next day, I was blessed to meet the person who would profoundly influence my music and my lifevocalist Pandit ${ }^{4}$ Shantanu Bhattacharyya. ${ }^{5}$ Indian spiritual tradition maintains that it is not the student who finds the Guru, but the Guru who attracts the soul of the yearning student. I soon came to realize that it was more than just coincidence that brought me to meet Shantanuji, and one year later I recognized him as my Guru.

As I walked the bustling streets of Kolkata, I realized that embracing the flow of life was not a choice, but the only option in order to survive here. Over the next two weeks, Andrew, Justin and I sat through twelve classes on the floor in Shantanuji's small music room and received a comprehensive overview of the basics of North Indian classical music. Most of the classes were over four hours long, and I struggled to sit peacefully and keep my discomfort from distracting me. Children of all ages came and went, and as the students got older, the material became exponentially more challenging.

For their first 10 to 15 years, students of Indian classical music are permitted to practice only sapat (scales) and 
paltas (patterns) in the 10 thaats (scales), with the exception of some memorized Raga music compositions. This music is practiced in one tonal centre (western key centre) standardized to best suit the voice or instrument: for example, males generally sing in $\mathrm{D}$ concert and females in B concert. This ensures that students master the technique of their instruments in relation to the fixed fundamental tonal centre and train their minds to withstand the intensive concentration needed in the advanced stages of training and performance. Although being an experienced saxophonist had its benefits, I realized that my Western music training did not ultimately prepare me to excel in these lessons. While my mind was intuitive and flexible, and I could create abstract and conceptual music in all key centres, these lessons demanded a very systematic, logical, and virtuosic proficiency based in one key centre only. This picture, above, shows a typical class in Shantanuji's home.

While applying my new experiences to creative improvisation, I felt that I was developing a unique approach, getting closer to "my own voice." Utilizing the outer structures of the ragas and talas (rhythmic beat cycles) for my creative explorations yielded interesting results, but this application soon felt a bit superficial. The maestros I met in India seemed to wield mystical powers and could create a mood so deep and tangible that listeners were drawn under their hypnotic spell: their virtuosic and melodic improvisations generated controlled cadences that surged towards an inescapable climax. How was it possible that one soloist could create a universe of expression in a limited collection of notes? I was more familiar with the flow and rhythm of creative jazz: the crying shrieks and calls of an unbound freedom, the conversational interaction of multiple voices, the collective searching for tension and resolution that relied solely upon the integrity of its members' intuitive connection.

Returning home from this life-changing journey, I was filled with endless inspiration for the next stage of my artistic development. Andrew, Justin, and I formed Monsoon to explore the synthesis of western improvisation with the complex and intricate modes and rhythmic cycles that our overview of Indian music had enriched us with. The band features Indian instruments like the tabla, bansuri, bass veena, and esraj (21-stringed bowed instrument), as well as saxophones, woodwinds, keyboards, and drums, creating a worldly aesthetic and producing a unique and innovative Indo-Jazz sound. After ten years of working together, we released out first album, Manadala, at The Glenn Gould Studio in Toronto on November 9th, 2014.

- Python's Tendency is a modal composition of mine that combines Indian modes with chromatic jazz improvisation. This is a video taken during the studio recording at Canterbury Music Company in Toronto on May 20th, 2014.

Click image below to watch video, "Python's Tendency":
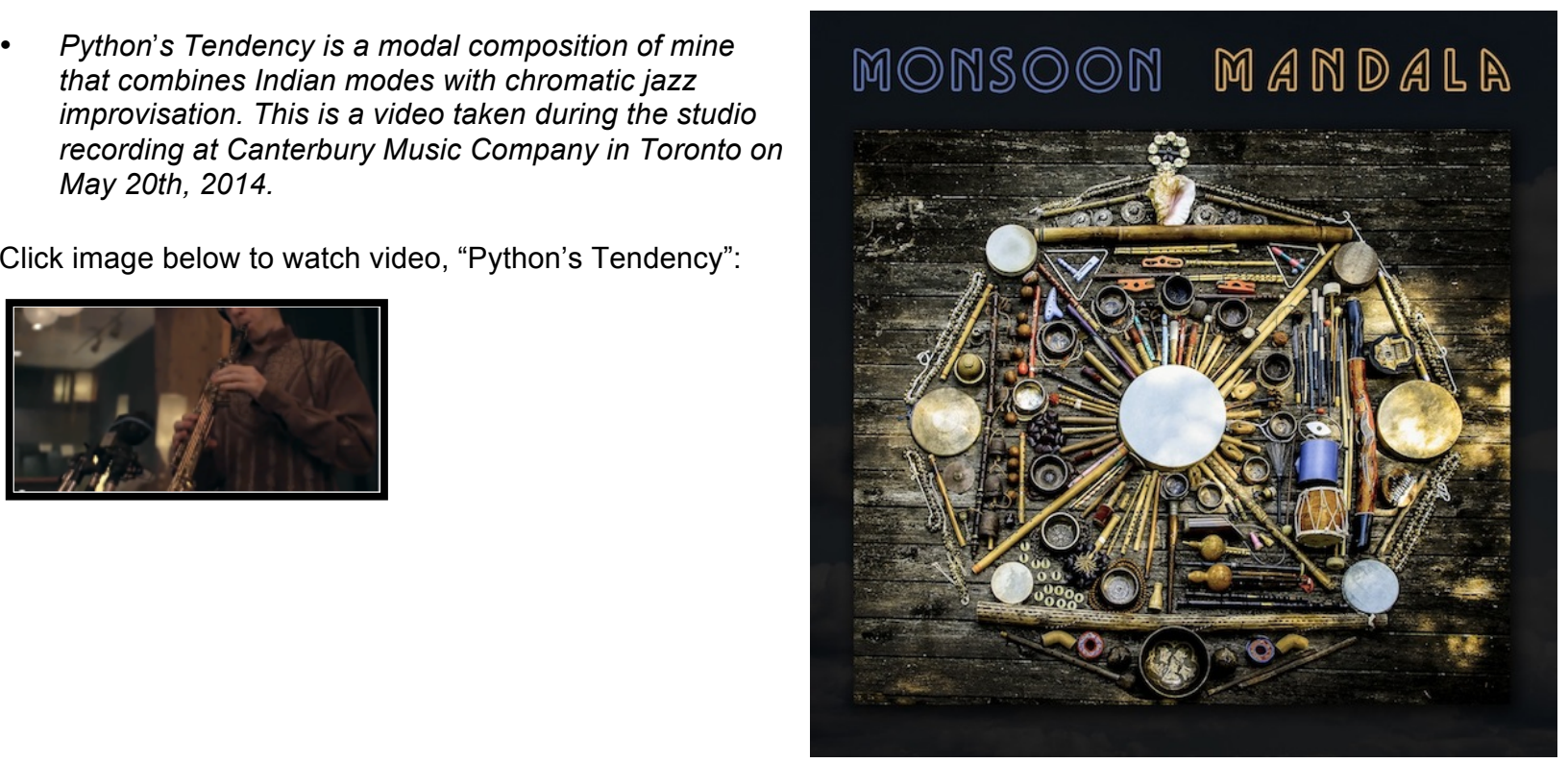
- $\quad$ Celestial Oceans is a composition based on the theme of the vast monsoon Raga Mian Ki Malhar. My saxophone solo starts with an improvised Raga alaap (free of time) developed over the tanpura and slowly expands into a chromatic modal jazz approach.

Click image below to watch video, "Celestial Oceans":

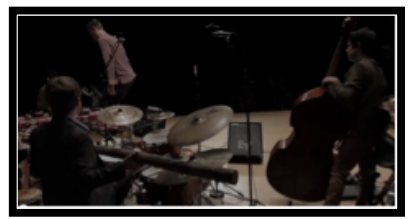

\section{Cultural Transformation and the Sacred Guru-Shishya Relationship}

In September 2007, Andrew, Justin, and I hosted Shantanuji, his wife Durba, and their 4-year-old daughter Mitra for the inaugural Toronto Indo-Jazz Festival, a festival that we founded in order to share our new love for Indian classical music and its synthesis with western contemporary music. Shantanuji was featured as the headline performer, singing both in a traditional presentation of ragas and as an improviser with Monsoon. During Shantanuji's week in Toronto, I was also fortunate to resume my raga classes from the previous year, proving to me the necessity of a mentor in learning this intricate musical language.

As my appreciation of the endless web of customs, rituals and formalities that surround Indian music developed, I started to recognize that Shantanuji was, more than a simple teacher, so selfless and unconditional with his time and wisdom that our relationship was evolving into the traditional bond between Guru and disciple. I thus respectfully asked Shantanuji to formalize my bond with him as my Guru. As I bowed down and touched Shantanuji's feet, giving him Pranaam (the traditional greeting of upmost respect), I entered into the sacred Guru-Shishya Parampara, a tradition that (since the Vedic period c. $1500 \mathrm{BC}$ ) has cultivated the highest spiritual values and their expression through art, music, dance, poetry and philosophy. I am blessed to have this sacred relationship with my Guru, to have received the true teachings and spirit of the ragas. Below is a picture of me accompanying Guruji on stage, learning in the true Guru-Shishya Parampara.

In 2009, Justin, Andrew, and I returned to India for a second time and spent three months training with Guruji everyday for an average of twelve hours. During this trip, we performed our first raga concerts as a trio, and to our surprise, were enthusiastically applauded for our efforts by the discerning audiences of Kolkata. Guruji assured us, however, that while our sentiment and sincerity were appreciated, we still had a long way to go to truly evoke the essence of the ragas. In one afternoon lesson, Guruji explained that while our Western ability to creatively improvise had its benefits, it also created confusion, as we seemed to be sourcing and expanding the raga from a modal perspective, not from the phase-based nature of his teachings. This constructive criticism, although challenging, helped me unravel the logical and rational habits of my Western mind and surrender to the Indian way of life.

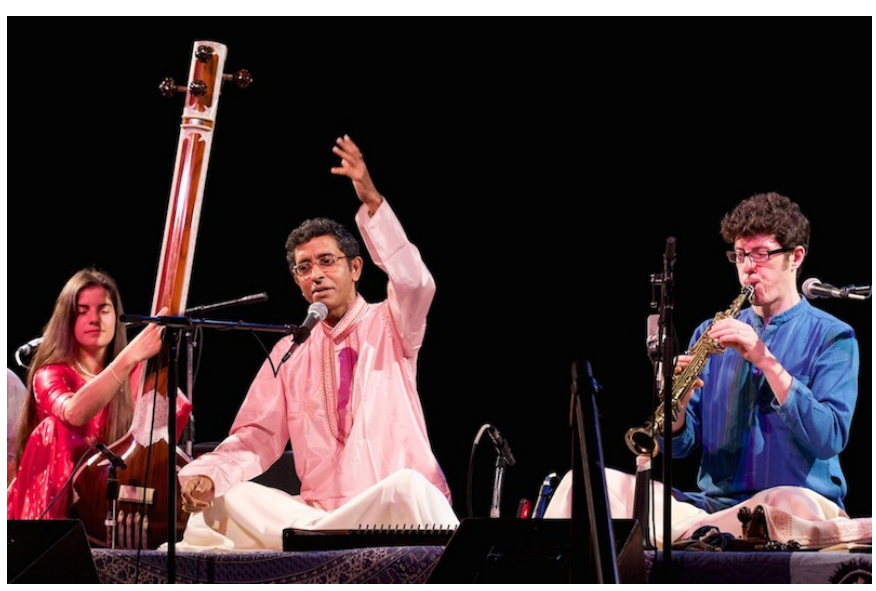

Since evoking the right mood is the sole purpose of a raga, I realized that learning the notes was not enough to reach my goal of traditionally rendering Indian classical music. Guruji taught a holistic cultural assimilation and integration that was, more than solely music, a way of life! I then began soaking up every nuance of daily life in India, from their local language and dress to their food and eating habits, from their ancient and complex religious ceremonies to their spiritual and philosophical beliefs. A musical Guru is the same as a spiritual Guru in that all aspects of one's life and music merge with that of the Guru. One's whole being must express the ragas, and thus a complete surrender into the life and talim (teachings) of the Guru is required. 
Below is the lineage of my Gurus (left to right):

Vidushi Meera Banerjee (tanpura- Shantanuji's Guruma) with Ustad Bade Ghulam Ali Khan (Grand Guru of the lineage, wearing hat)

Guru Jnan Prakash Ghosh (Prasunji's Guru)

Pandit Prasun Banerjee (Shantanuji's Guru)
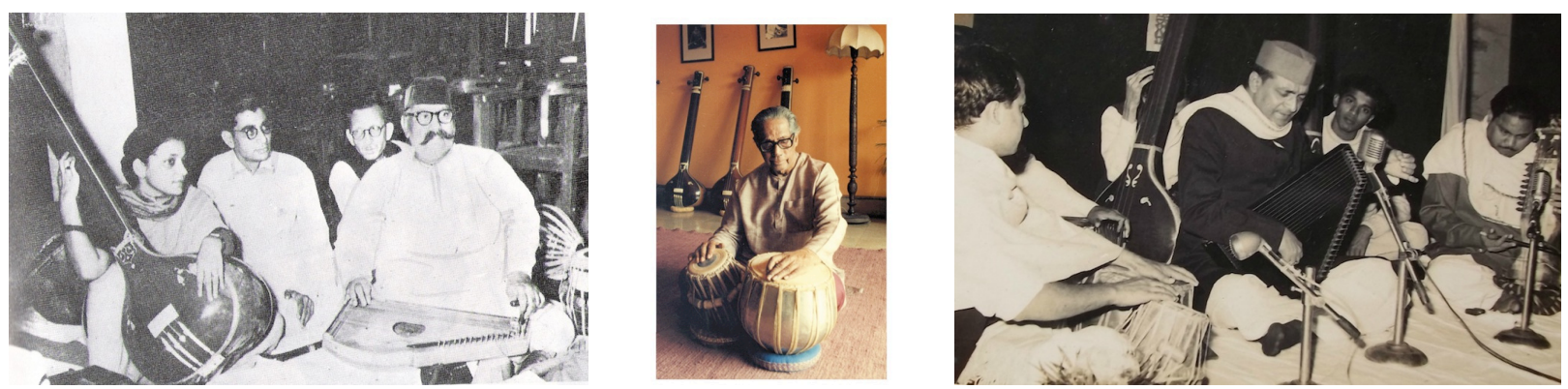

It was only after years of living in Kolkata, in devoted practice to the traditional life of an Indian raga musician, that I began to understand the cultural and spiritual context from which this music flows. In 2010 , I surrendered to an intuitive call and moved to India with my brother Andrew with the intention of staying until I could absorb the ragas into my very being. Since then, I have been welcomed into Shantanuji's home and become a part of his family. In gratitude for Guruji's unconditional offering of his musical expertise, I became part of his daily life, offering work by helping in whatever way the family required, as well as accompanying him to countless concerts and tours around India and Canada.

Below is Shantanuji's full performance of Raga Sudh Sarang, recorded live in 2010 for the West Bengal State Music Academy Music Conference at the Rabindra Sadan theatre in Kolkata. Andrew and I accompanied on tanpura.

Click image below to watch video, "Raga Sudh Sarang":

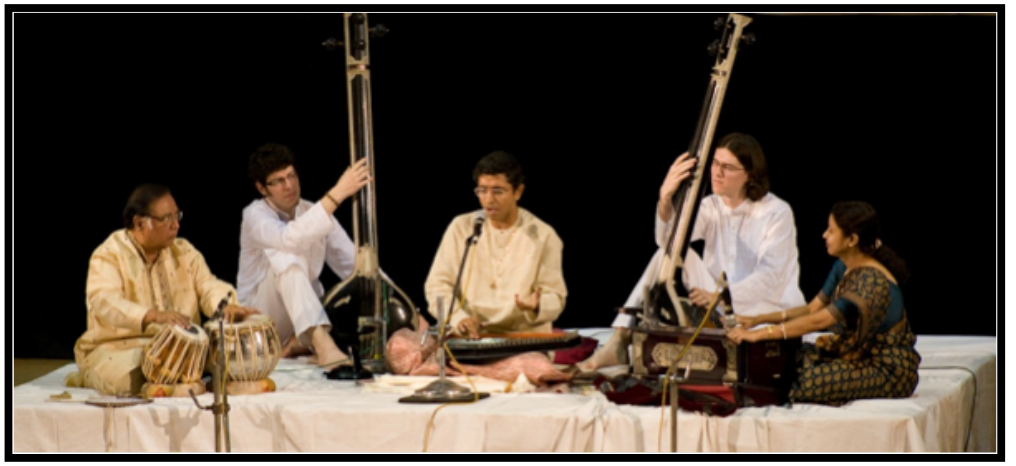

\section{Learning Raga Expression}

The length of this training period is up to the Guru: once you have properly internalized your training, you will be given their "blessings" to become a performing artist. Guruji strongly believes that during the initial stages of learning, every moment should be observed by the Guru to ensure that only the correct elements are being practiced and internalized. I feel so fortunate to have come under the guidance and care of Guruji, as it can be difficult to find a Guru willing to do this tedious work. His patience and understanding also allowed me to achieve one of my major goals: applying the language of raga to the tenor and soprano saxophones.

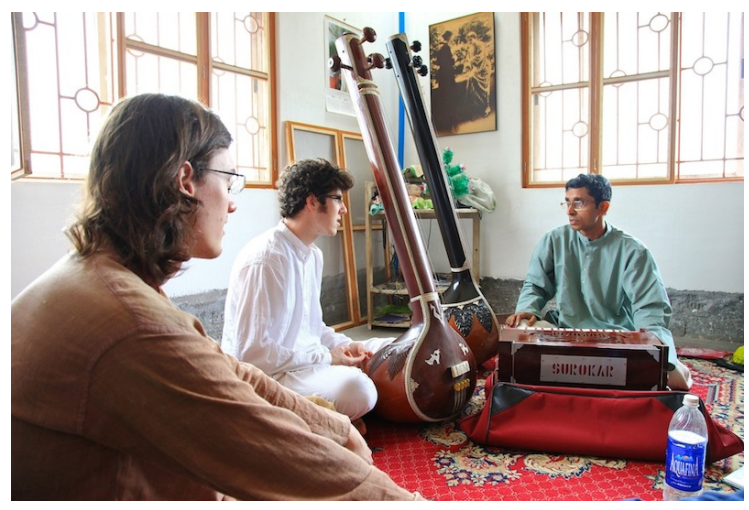


The learning system of ragas is generally call and response. The Guru will sing or play the melodic phrase and the student will imitate that phrase in all its intricacy: timbre, tuning, tempo, dynamics, style, nuance and sentiment. The essence of Indian raga expression is contained in a vocal style called gayaki, and all great Indian instrumental maestros can sing anything they play. Singing has been a large part of my training, and my greatest tool in realizing the deepest form of raga expression before applying it to the saxophone. Only now I have come to realize how fortunate I have been to have a vocalist for a Guru.

The precision required to produce the traditional mood or feeling of a raga is such that students must study each one for years before they are ready to perform publicly. In my first years of intensive training, I studied only one raga: Yaman (grouped in the Kalyan thaat, equivalent to the western Lydian scale). Its movement follows a strict upward and downward scalar pattern that is never compromised. The basic movement omits the 1st and 5th degree of the scale on ascent, but includes all 7 notes on descent. However, the raga depends on much more than this: internalizing the core melodic phrases within this collection of notes is of utmost importance, and once understood, these phrases follow a consistent musical behaviour that becomes the essential body of the raga.

Guruji has taught that the essence of a raga is contained in its traditional bandishes (song forms with lyrics), and over the years I have learned over 30 compositions in Raga Yaman alone. These compositions cover the entire range of Classical Indian music evolution and include an ancient Dhrupad composed by Mian Tansen (1506-1589), a Tarana composed by Bahadur Hussain Khan (b. 1850), and Khayal bandishes composed by Bade Ghulam Ali Khan (19021968), Jnan Prakash Ghosh (1909-1987), and Prasun Banerjee (1926-1997) as well as vocal and instrumental compositions by my Guruji. Informed by traditional bandishes, the musician improvises a raga's vistaar (expansion and development), although the style, ornamentation and treatment of the raga varies depending on the gharana (lineage) of the Guru.

The beauty of raga is in its unique ability to be transcendental, universal, and timeless while simultaneously reflecting the artist's relationship with contemporary culture: indeed, it has always thrived when musicians such as Amir Khusrow (1253-1325), Mian Tansen, or Allauddin Khan (1862-1972) have revolutionized its expression. I am especially inspired by Bismallah Khan (1913-2006) and Pannalal Ghosh (1911-1960), two recent pioneers who mastered respectively the shehnai (double-reeded woodwind instrument) and the bansuri, showcasing for the world how raga can be expressed on woodwind instruments such as the saxophone. Another inspiration is Ranadhir Roy (1943-1988), who designed a larger form of the esraj more suitable for classical music and pioneered a new playing style. I believe that raga music can be played on any instrument as long as the musician trains with a realized Guru and immerses in traditional Indian culture.

Pictures (left to right): Bismillah Khan, Pannalal Ghosh, Ranadhir Roy
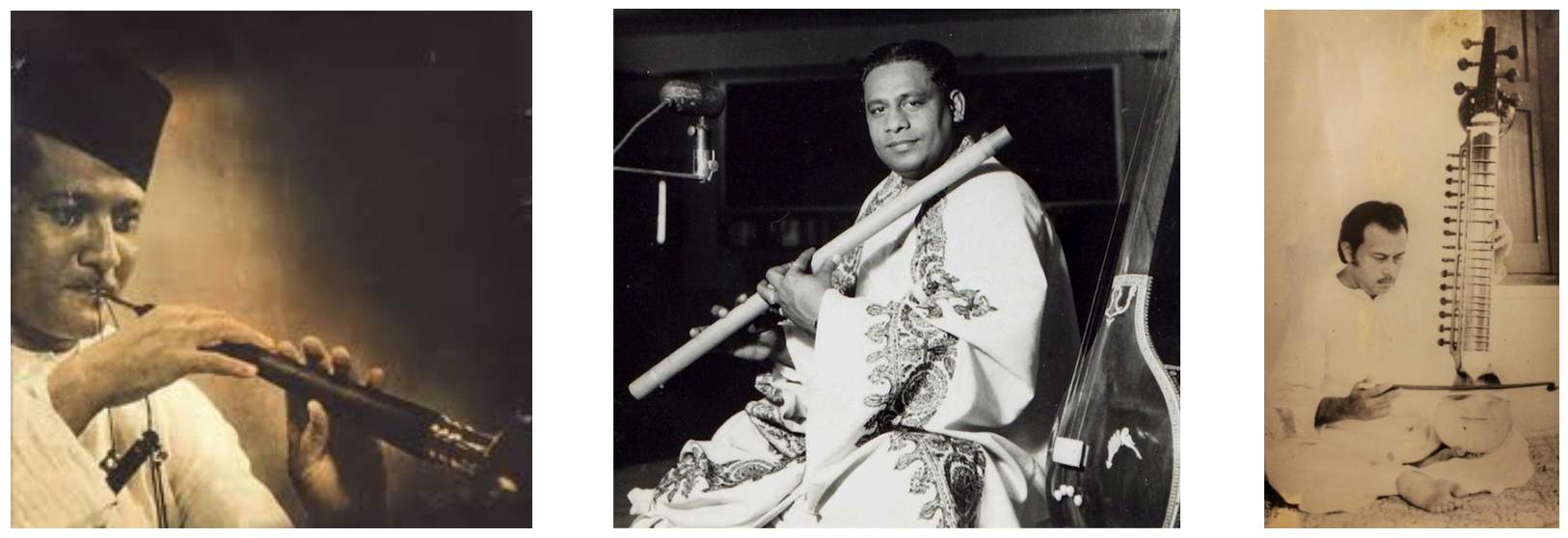

Below is a short clip of me accompanying my Guruji on esraj in a traditional raga concert, where my role was to follow and imitate every one of his phrases. Imagine how invaluable this learning experience was! I could easily relate to my Guruji, who would refer to accompanying his Gurus on harmonium (compact pump organ) as his most important learning experiences. 
Click image below to watch video, "Raga Purvi":

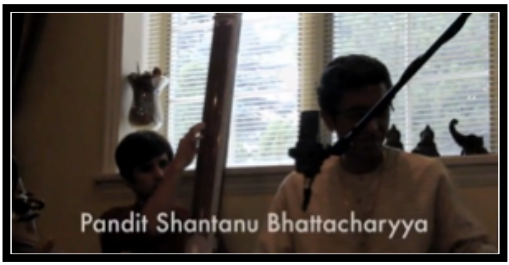

\section{The Evolution of Raga on Saxophone}

To properly convey on saxophone the delicate nuances and inflections of the ragasalankart (ornaments), gamak (heavy accent note from above or below), mulki (grace note), and especially the meend (bending and smooth gliding between notes)—I needed to innovate a new playing style by exploring many extended techniques and alternate fingerings. Furthermore, in order to express the non-tempered nature of tuning and shrutis (micro-tonal tuning) of a raga, I added micro-tuning adjusters and modified the key heights to overcome the temperament of the saxophone's Western tuning system. Working for over 6 years in the Cosmo Music woodwind repair shop in Toronto, under the mentorship of head repair technician Kevin Rohm, provided me with the appropriate technical knowledge to creatively make some of these adjustments, leading me to co-design with Kevin what I call the "Shrutiphone", a nontempered saxophone with a tuning system appropriate for Indian drone-centric music.

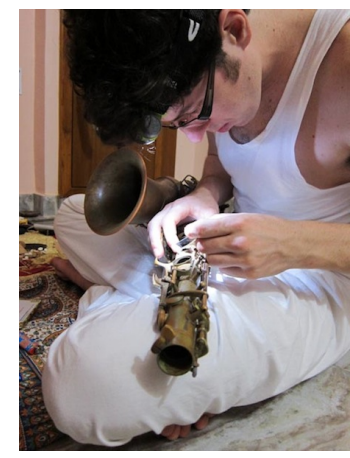
I believe the Shrutiphone is the first innovative step forward in the evolution of North Indian classical music on the saxophone.

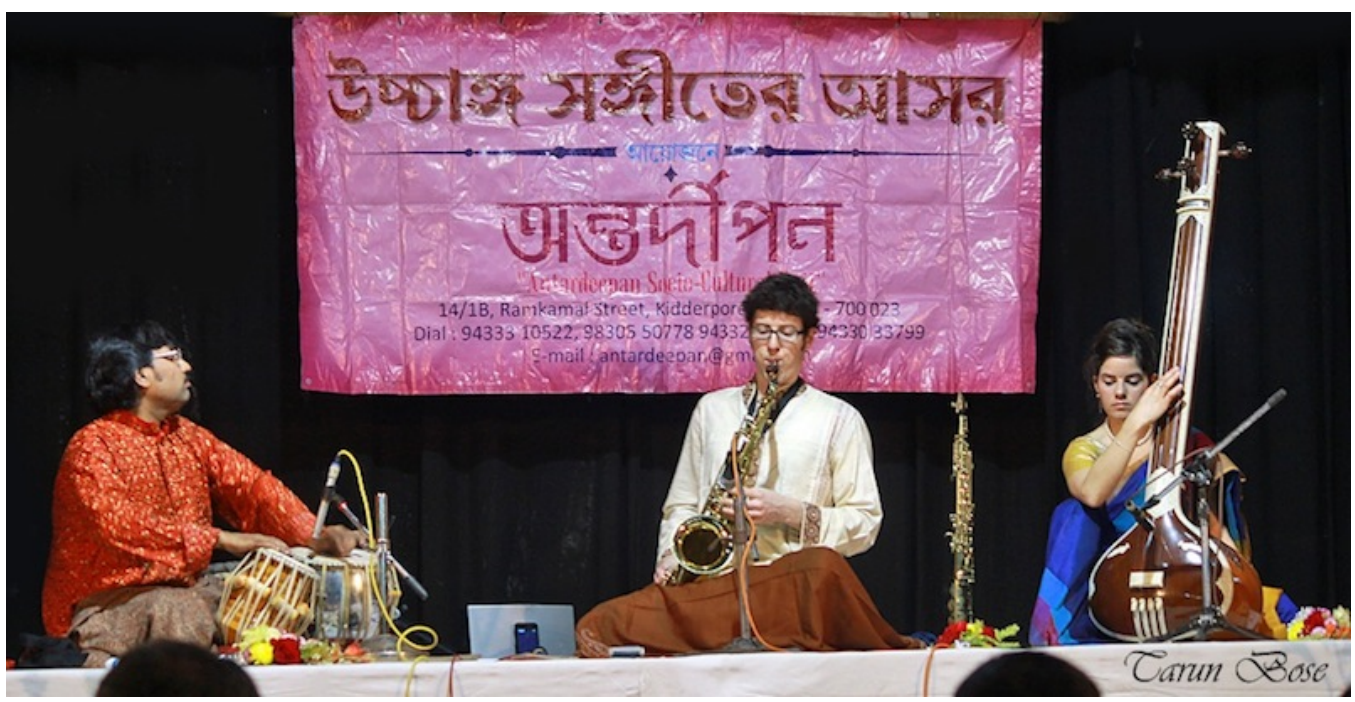

To further help realize the ragas, I have also learned the bansuri and the esraj. Multi-instrumentalism, although considered by many in India as a distraction from mastering one instrument, has been an invaluable tool for me in expressing on saxophone the sentiment and techniques of gayaki (vocal) and tantrakari (instrumental).

The bansuri, as a woodwind instrument, naturally parallels the saxophone in sound production and playing technique, and by learning the vocal style from my bansuri Guru, Sudip Chatterjee (right picture), I have been able to more accurately apply these exact nuances to the saxophone. I have found that the bansuri acts as a bridge, allowing me to master woodwind playing techniques appropriate to the instrument as well as the sentiment of any given raga.

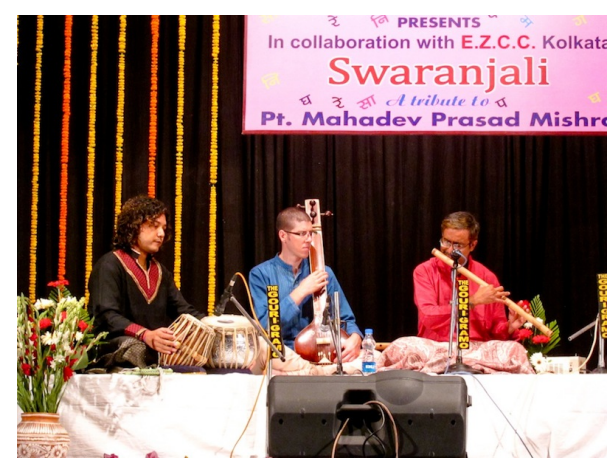


The esraj, a bowed instrument, comes closest to replicating the style and movement of the human voice. Practicing it has given me valuable insight into the floating nature of the swaras (notes) and the exact positions of their shrutis (micro-tonal tuning) and taught me how to adapt into a suitable playing style the subtle "curves" intrinsic in the voice. I have also learned from my esraj Guru, Abir Singh Khangura, a style that combines gayaki and tantrakari. This experience has allowed me to create a more balanced performance style that enhances the natural strengths of the saxophone with the essence and sustenance of the voice.

\section{Performing Indian Classical Music on the Saxophone}

The rendering of traditional North Indian classical music on saxophone has become an increasingly important aspect of my musicality. I have performed solo, as well as alongside my brother Andrew and Justin, at some of India's oldest and most respected music festivals and conferences.
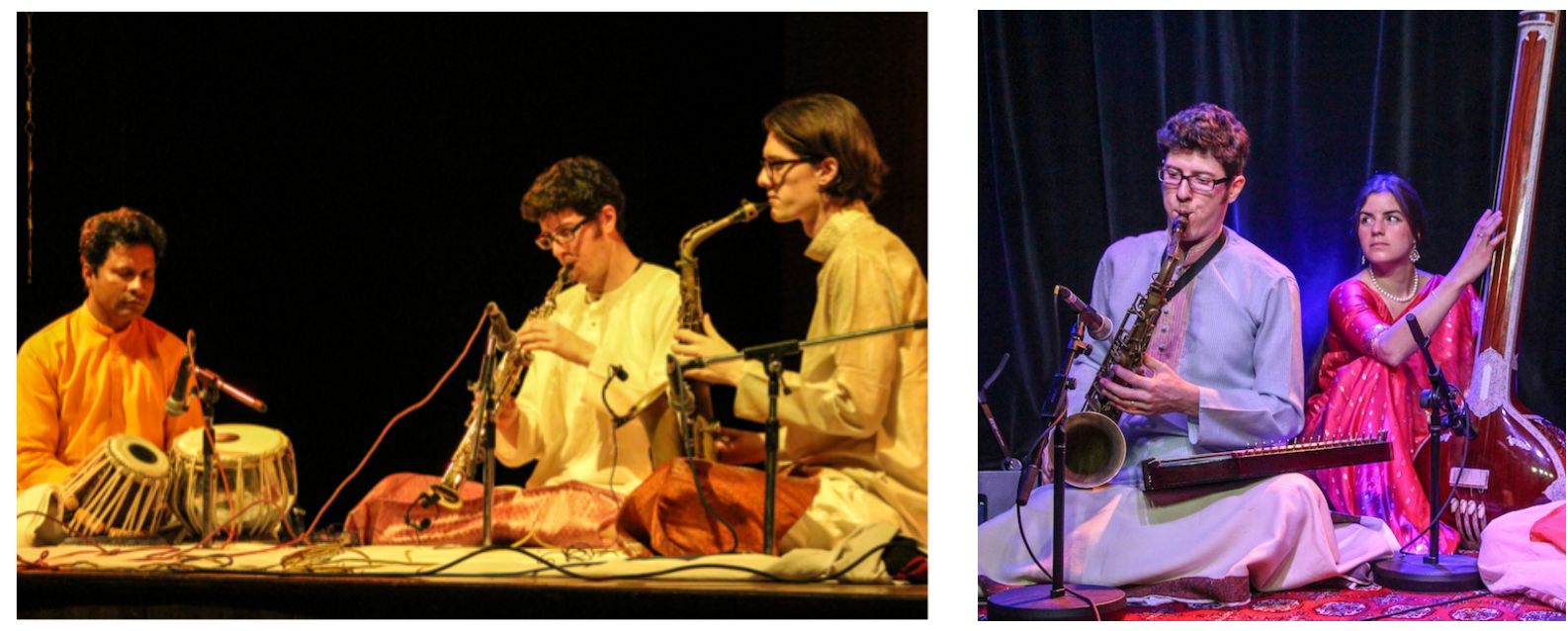

- $\quad$ Raga Marwa - Alaap, Rupak Taal, Drut Tintal and Jhala. These clips are from a recent performance by The Monsoon Trio and feature the most current model of the "Shrutiphone". In this performance, I demonstrate the more intricate nuances and ornamental style of Raga Marwa and, at the end, develop the jhala: very fast rhythmic patterns that demand innovative articulation techniques.

Click image below to watch video, "Raga Marwa-Jonathan Kay":

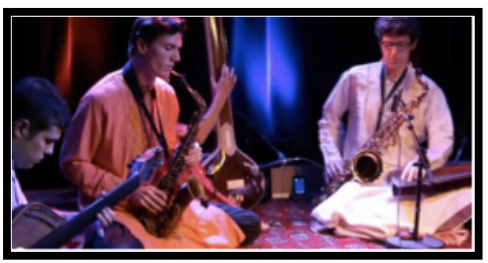

- $\quad$ Raga Bilaskhani Todi-Vilumbit Ektaal, Madhya and Drut Tintal. This late morning raga is one of the most mournful and pathos filled of melodies. This concert was part of one of Kolkata's most prestigious classical music conferences: the Ballygunge Maitree Music Conference. Andrew and I were honoured to be the first saxophonists invited to play there, to have the opportunity to demonstrate how our instrument is capable of delivering professional quality Indian classical music. This performance showcases, in particular, an unprecedented degree of fluid vocal bending (meend) on the soprano saxophone. 
Click image below to watch video, "Raga Bilaskhani Todi-Jonathan Kay":

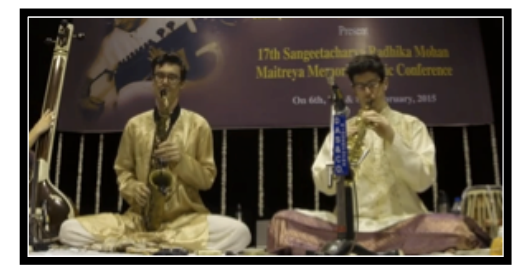

- $\quad$ Raga Jaijaiwanti is a romantic evening raga set in the monsoon season. This concert features one of India's greatest tabla maestros, Subhankar Banerjee, and marks the first saxophone recital ever with a musician of his stature.

Click image below to watch video, "Raga Jaijaiwanti":

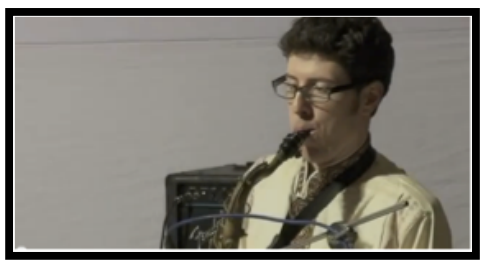

\section{Part Two: My Sadhana}

In the tradition of Indian culture, Sadhana is the individual journey towards spiritual fulfillment, a holistic movement that aims to harmonize and focus all actions towards this goal. In India, music is regarded as one of the most effective forms of Yoga, or union with the Divine. This Nad Yoga is the source of my Guruji's music and teachings, and in following his example, I too have taken music as my Yoga and Sadhana.

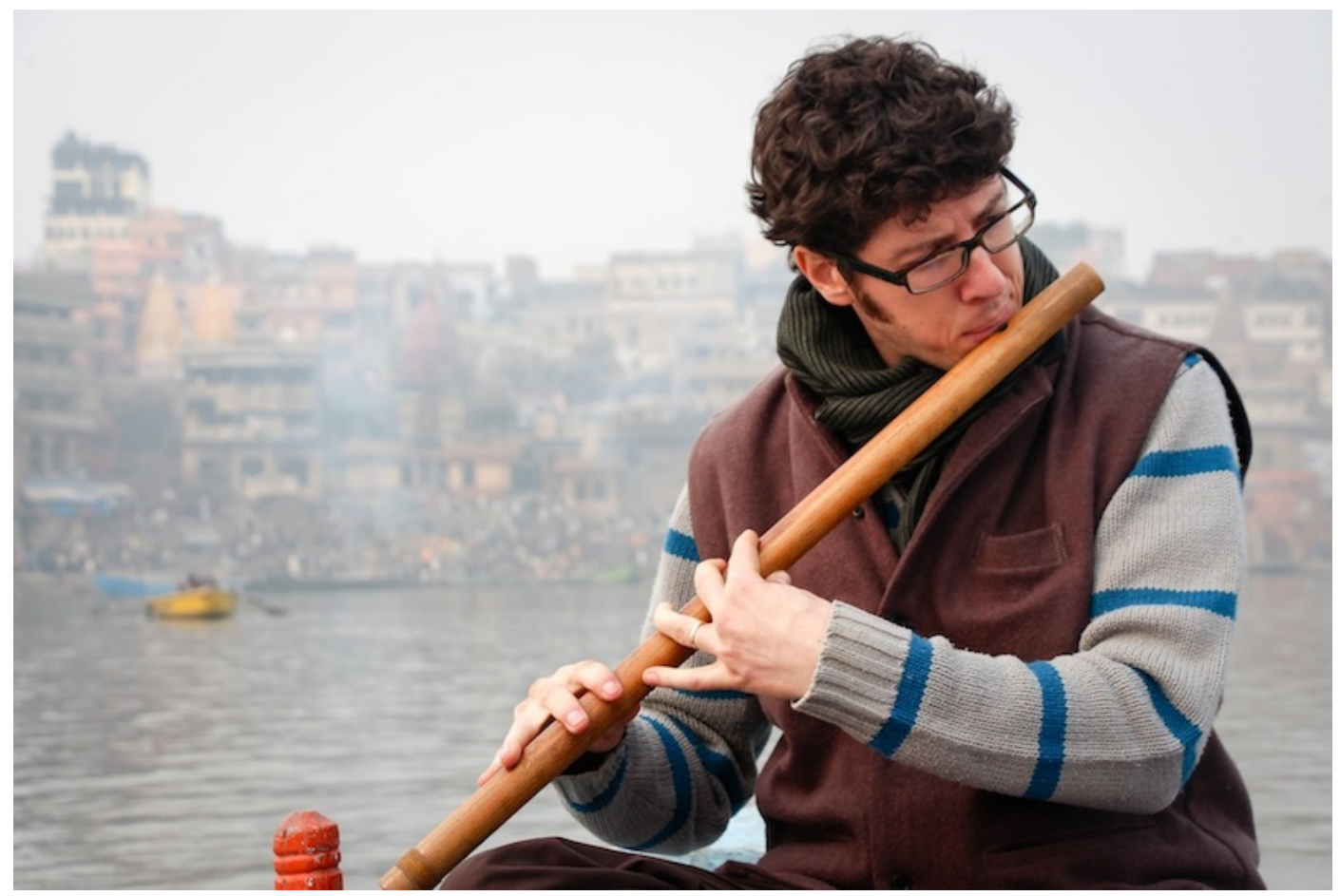




\section{Traditional Classical Art and Contemporary Non-Classical Art}

Traditionally, performing a raga is like classically painting a portrait of a personality known and loved by all. The unfolding of the rendering, identifying with every detail and with the broader mood (rasa) of the raga, is what the Indian music lover expects. Each performance of Raga Yaman, for example, creates a musical 'portrait' of the same personality with the same major features consistent with the tradition. The crucial elements that truly bring a raga to life are artistry and improvisation, the use of nuance and ornamentation to enhance and beautify the 'portrait' in each rendering; therefore no two portraits are exactly the same, but the essential mood is consistently recognizable. These classical Ragamala paintings, dating from the 16th and 17th centuries, were the first attempts to capture the essence of a raga in a visual form, each aiming to depict the mood and time of day or season of the specific Raga.
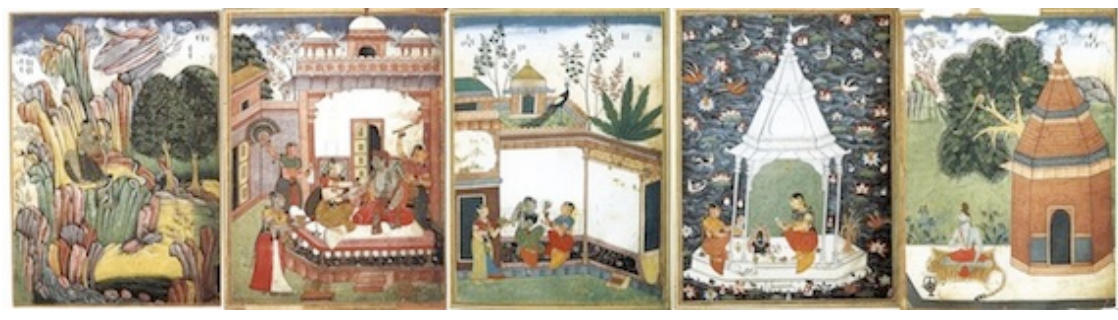

Improvised music is more like a painting that has not been conceptually premeditated or contrived. The result would be more of an impressionism-of-themoment, of one's interaction and reaction to other creators, of a spontaneous creative construction reflecting one's current state of being. Modern, creative jazz obtains limitless variety and diversity from the basic motives of individual artists who draw inspiration and material from any literal or conceptual aspect of life-to me, this is one of the greatest strengths of contemporary Western art.

With these two methods of painting firmly in mind, I began to understand how the artistic process differs drastically between classical and non-classical art and why the mentality of the Indian classical musician is fundamentally different from that of a contemporary jazz musician. Classical raga music is a sacred art form that stems from thousands of years of Indian civilization, one of the greatest gifts that India has offered the world, and one must be in relation to this to identify with it. Raga is a system that precariously balances past tradition with modern interpretation: the musician has a predefined motive and specific language of development to follow, but the integrity of the music lies in the moment of creation, in spontaneously bringing the raga to life.
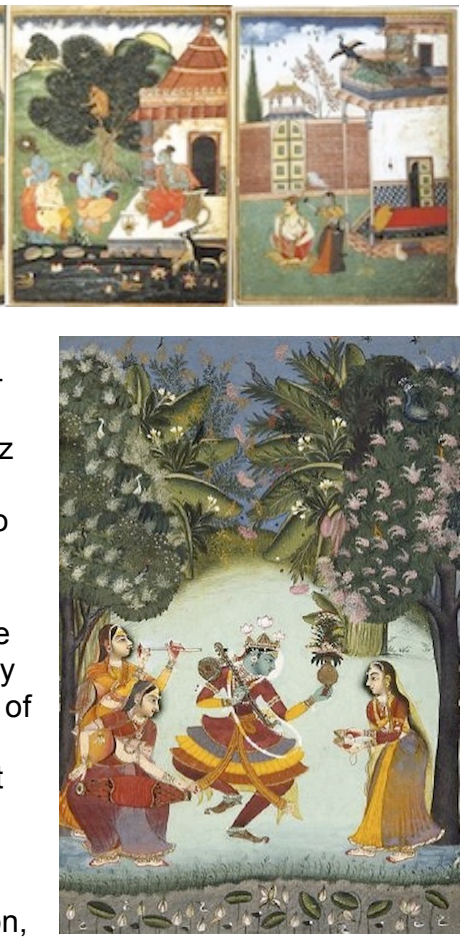

Visualize the role of improvisation in classical and non-classical music forms. If freely improvised music and creative jazz lie at one end of a spectrum, then the other end would inevitably be secured by Western classical music, where there is variation only in the interpretation of a defined composition. I would place North Indian raga music in the middle of the spectrum: it balances in harmony the best attributes of classicism, retaining the continuity of past and tradition while respecting artists' intuitive and improvised interpretation of the present.

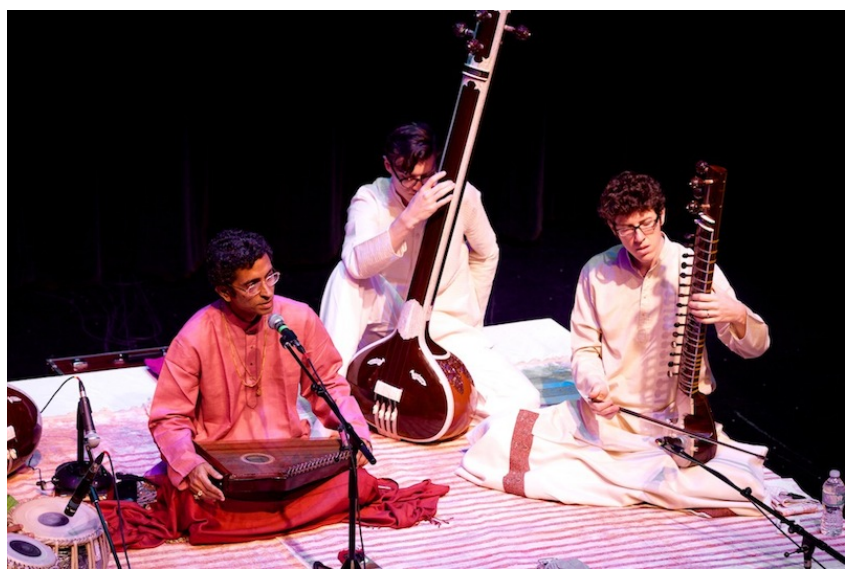


A basic representation might look somewhat like this:

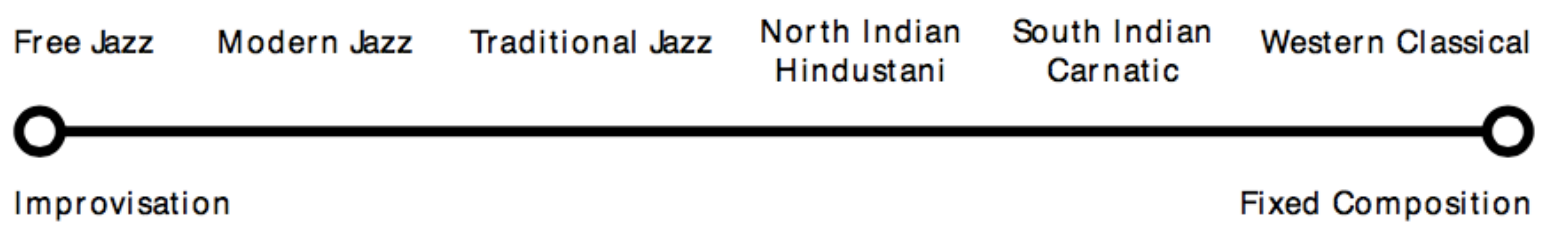

\section{Raga Sadhana}

"I do have to say, however, that if you truly want to understand and learn (Indian) classical music, you have to live in India and learn it there. There are no two ways about it."

\section{Pandit Hariprasad Chaurasia (Chhibber)}

The traditional teaching of my Guruji has challenged me to follow a way of life inseparable from my music, which differs drastically from my previous training at Humber College for Jazz Studies, where lifestyle and musical aesthetics were separate matters. The learning process of Indian music is not exclusively musical. Guruji has taught me that perfection in music depends on personal holistic harmony-physical, emotional, psychological and spiritualand by perfecting every action, we can create within ourselves a greater harmony of which our music is but a reflection.

Many years spent immersed in this culture and lifestyle has deepened my understanding and internalization of its music. Since Indian music was born from the same spiritual source as their religion, I have found that the more I identify with Indian spirituality and religion, the more I can relate to the deep devotion integral to its expression. Their classical music tradition is laced with formalities, customs, hierarchies and rituals that reflect a deeply religious culture. Some would observe that the traditional lifestyle of a raga musician is a religion itself, one of surrendering to the lineage of Gurus, worshiping instruments, and offering music to God.

My cultural immersion has had other positive impacts on the authenticity of my Indian music expression. Music is so interrelated with language that even within Indian states musical expression will change based on the musician's mother tongue ${ }^{6}$. I am not fluent by any means, but I have achieved some facility with Hindi (the vocal language of Indian classical music) and Bengali (the local language of Kolkata), with the structure, flow, and sentiment that guides their thought processes and expression, which has greatly influenced my musical phrasing, structure, and emotion.

In listening to music outside of practice and performance, Guruji taught me many stringent but necessary lessons. For example, in order to better internalize his teachings, he advised that it is better at first to not listen to other forms of music, to better aid the internalization of the raga subtleties and sentiment, and for years I have followed this advice as best as I can. When I was focused on one raga, Guruji said I must listen to only that raga as performed by only a handful of top maestros whose approaches reinforce his own.

A unique element of North Indian classical music is that each raga must be performed during a specific time of day or season: Raga Yaman, for example, is performed between 8 and 10 pm, and Mian Ki Malhar is performed anytime during the monsoon months of July to September. Guruji taught me to cultivate the spirit of each raga in relation to the natural colours and human emotions and sentiments that correspond to its setting. While living in India, I have been fortunate to experience how ragas depict their natural environment and can reflect the artist's inner state at that time.

My music has also been enriched through intimate experiences with the regional cultures from which Indian music traditions were born: the Rajput palaces and courts where Dhrupad music once thrived, the desert sands of Rajasthan that folk music tells tales of, the Bengali countryside where Baul musicians roam and Bhatiyali boatmen sing, the ancient temples deep in South India where choruses of monks chant thousand-year-old sacred hymns, and the tallest peaks in the world where bansuri players play the song of the Himalayas. Shot in Varanasi, the holy pilgrimage site for Hindus, the video, right, shows me playing the bansuri in a boat on the Ganges.

Click image below to watch video, "Bansuri on the Ganga, Varanasi":

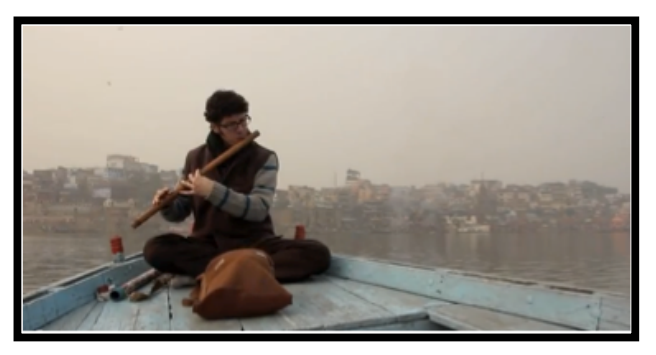




\section{Two Houses}

As my understanding of Indian music grew, so did my aspiration to find common ground with Western creativity. Drawing from the cumulative reservoir of my experience benefited my creative approach far beyond my expectations, but to my surprise, I reached a point where this reservoir of East and West also caused me much misunderstanding and misdirection in approaching traditional raga music.

After about a year of study in India, Guruji expressed his concern that my natural ability to improvise did not seem to aid me in the proper development of a raga. This made me question if there could even be a conceptual bridge between jazz and Indian classical music! He assured me that aspects from my improvising background would play an important role in my development, but he was more concerned with how I internalized and then improvised upon the essence of his talim. Guruji reviewed recordings of my performances, trying to find the source of my meandering voice. He concluded that because Indian music is born from the Indian consciousness on Indian soil, my native musical instincts had little relevance at this stage, and thus asked me to compartmentalize myself into two houses. Respecting all that I was and aspired to be as a creative, Western musician, he asked me to start from scratch and build another house of raga music. In retrospect, this was a defining moment in my journey.

The musicianship of Indian classical music is rooted in years of practicing logical patterns (paltas) within different beat cycles (talas). I began to see that this practice gives musicians more than just technical virtuosity; it also guides their improvised storytelling. I started practicing these patterns religiously, and with vigilant guidance from Guruji. At first, my improvised raga expansions lead me on wild melodic adventures resulting in meandering stories that lacked the internal logic necessary to develop a meaningful raga theme. Guruji helped me see that improvisation in Indian music is built upon an intuitive logic and natural symmetry, what is known among Indian musicologists as architectonics.

One imperative characteristic of raga music is that for phrases to have the greatest impact, one must perfect the sur (tuning) of each note, specific in each raga, which flows from an awareness and oneness with the tanpura. The cultivation of this constant, subtle inner vibration becomes a fundamental state of being, and once mastered, the mood and spirit of a raga can literally charge the atmosphere of a room. My heightened sensitivities to the tuning system of the ragas have not only improved my tuning to a drone (or fixed pitch), but also made me more aware of the compromises inherent in the Western tuning system.

Under Guruji's guidance, and that of other maestros who have authenticated my approach, I have built my raga house upon the solid foundation of traditional Indian teachings.

\section{A Question of Faith}

My journey into Indian culture and music has challenged my very motives for creative and artistic expression. At the end of our very first class, while Andrew, Justin, and I sat in silence over a cup of Darjeeling tea, Guruji stated he felt strongly that we had met before, that our souls had travelled together in a past life. To him, this feeling came as an intuition from a reality beneath the surface of the physical and psychological levels my Western mind was used to perceiving. I was shocked by the honesty and simplicity with which he stated this, as though reincarnation and the existence of a soul was common knowledge, but I was also not about to take any statement on blind faith, and thus began for me a passionate inquiry into the world of Indian philosophy, psychology, and religion.

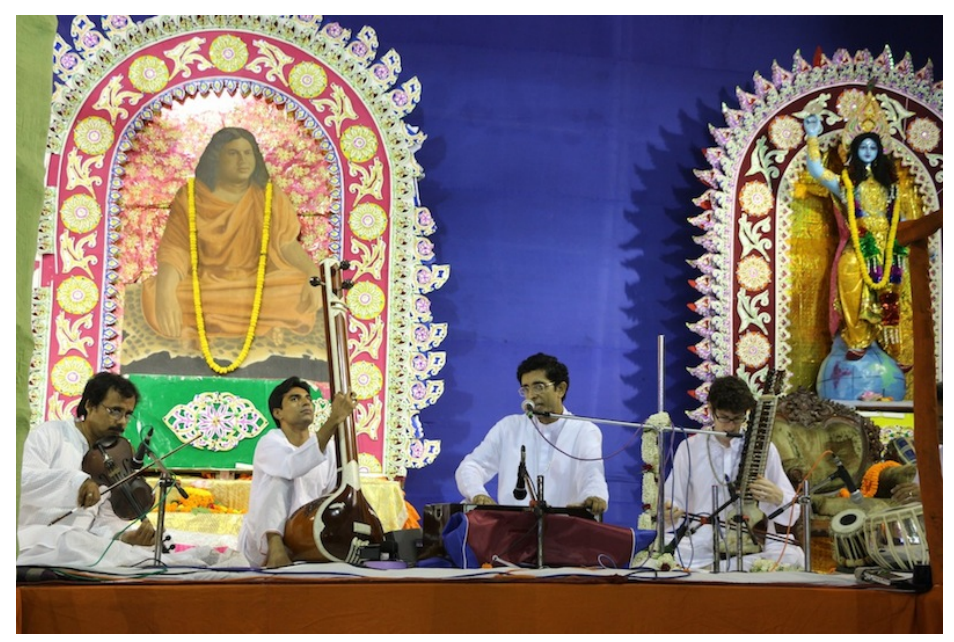

According to the spiritual and mystical teachings of the Gurus, a raga is, more than a mood or emotion, a conscious entity cultivated in relation to a transcendental aspect of consciousness, a vibrational representation of higher and more subtle planes of existence. As a scientific-minded Westerner, I questioned this characterization deeply at first, but then realized that I was not going find spiritual truth in the intellectual realms of the mind.

I ultimately found the "subjective science" of yogic traditions, in particular the Integral Yoga of Sri Aurobindo, most helpful in approaching this phenomenon. I simply stepped back from my own sensory experience and mental 
perception and observed how a raga interacted with various planes of my being: my physical, emotional, and vital beings; my sensing, intellectual, and intuitive minds; and my higher spiritual being. As my practice of Nad Yoga progressed, I could feel how the harmonization of the raga phrases with the tanpura also began to harmonize my inner nature, changing my perception of the physical environment and my own state of being, confirming for me that ragas are indeed vehicles of transformation and spiritual transcendence, what Guruji described to me as "the raga consciousness."

Respect to this lineage is symbolized by touching the Guru's feet, a ritual called Pranaam. By surrendering to the physical Guru, one is also paying homage to the far greater wisdom of the "Guru consciousness." This surrender is the highest act of yoga, and has helped to purify my ego and cultivate a reverence for the knowledge and wisdom I have been privileged to receive and share.

The spiritual faith that has grown in me over the years has become an important aspect of who I am. This faith was born from insistent questioning of experience and perception. I found raga music a most helpful tool, allowing me to remain open to all possibilities beyond surface appearances, while maintaining a systematic and experiential method of observation and progress.

Below is a picture of Andrew and I performing ragas at a traditional baitak (house concert) as our Guruji listens intently in the front row.

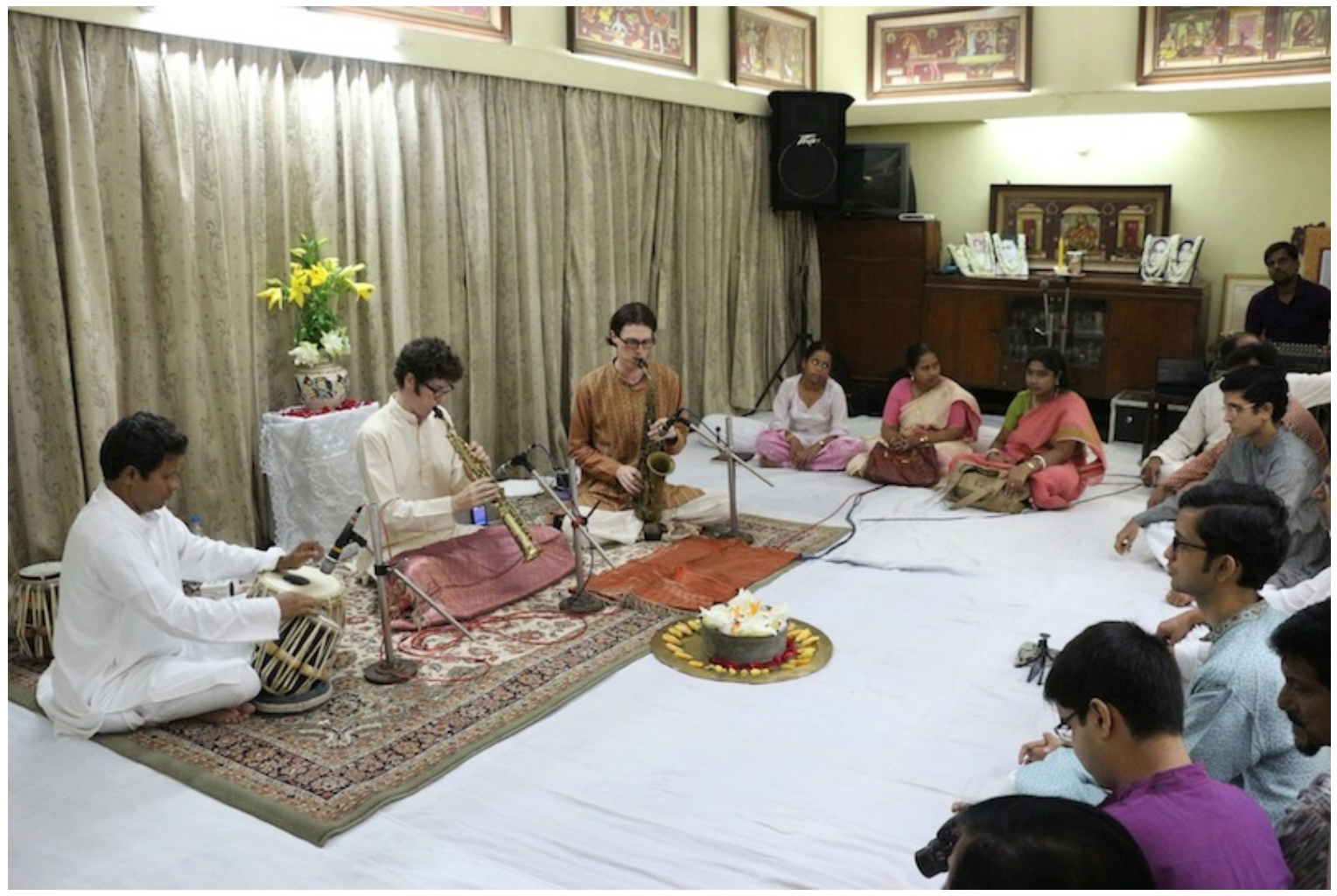

\section{Part 3: An Integral Synthesis}

\section{Searching for a "multi-cultural theory of musical transcendence"}

My immersion into raga music has yielded wonderful moments of classical expression; nevertheless, when I have disregarded rules, formalities, etiquette, and tradition and offered this knowledge to my creative side, I have composed and performed music that depicts the unique common ground of East and West that exists within me.

At the crux of this East-West intersection, I was fortunate to rediscover my first musical inspiration: the great visionary John Coltrane. ${ }^{7}$ Coltrane had a spiritual awakening in 1957 and began devoutly pursuing the study of Indian religion, philosophy, and music. In 1964, with the release of A Love Supreme, Coltrane's music became an extension of a spiritual path by which he aspired to higher cosmic truths and ideals. This later period of Coltrane's music, previously 
too abstract and intense for my sensibilities, was now full of life, beauty, and profound artistry. What allowed this change in my perception? After much wondering, the answer suddenly became obvious: it was in the intent of the music. Coltrane's progressive musical and spiritual realizations cried out for truth, for the descent of divine grace and the betterment of humanity, and thanks to my raga studies in India, I had become receptive to his message.

On the surface, the chaotic primal energy of Coltrane's cries bears no resemblance to the serene and contemplative mood of a raga, but for me both contain the same core intention. In the context of Indian philosophy and religion, Coltrane was a mystic, a shaman, a tantric sadhu ${ }^{8}$ using music to connect to the cosmic consciousness:

My goal is to live the truly religious life, and express it in my music. If you live it, when you play there's no problem because the music is part of the whole thing. To be a musician is really something. It goes very, very deep. (qtd. in Devito 337)

My music is the spiritual expression of what I am - my faith, my knowledge, my being ... (qtd. in Devito 337)

When you begin to see the possibilities of music, you desire to do something really good for people, to help humanity free itself from its hangups ... I want to speak to their souls. (qtd. in Baham 153)

All a musician can do is to get closer to the sources of nature, and so feel that he is in communion with the natural laws. Then he can feel he is interpreting them to the best of his ability, and can try to convey that to others. (qtd. in Baham 51)

Coltrane's spiritual journey was interwoven with an investigation into world music, with a search for a "multicultural theory of musical transcendence" (Berkman 44). He believed not only in a universal musical structure that transcends ethnic distinctions, but also in harnessing cosmic energy through music itself:

I want to be able to bring something to people that feels like happiness. I would love to discover a process such that if I wanted it to rain, it would start raining. If one of my friends were sick, I would play a certain tune and he would get better; if he were broke, I would play another tune and immediately he would receive all the money he needed. But what those pieces are, and what way do you have to go to arrive at knowing them, I don't know. (qtd. in Devito 182)

Coltrane was clearly searching for the same musical/mystical powers described in many legends from India about great saints and musicians. The most famous legend describes Mian Tansen (1506-1589) who upon request from the Mogul emperor, Jalal ud'din Akbar, displayed his powers by singing Raag Deepak, which created fire to light the lamps in the courtyard, and who thereafter brought the rains by singing Megh Malhar.

In the liner notes of Live at the Village Vanguard, Coltrane says, "I've already been looking into those approaches to music-as in India in which particular scales are intended to produce specific emotional meanings" (qtd. in Hentoff). Although he had just begun to study with Ravi Shankar before he died, it is clear that Coltrane was greatly inspired by the mysticism of India. In interviews recently released by the Ravi Shankar Foundation, Raviji speaks of his association with Coltrane:

He had heard me perform and had most of my LP records that were available and was told by Dick Bock that he was a great admirer of mine and Indian Classical Music! In our sessions he asked me many questions about the basis of our music: the way we learnt from the beginning, how much was written down, how much was memorized, how much was fixed, how and when we started improvising, etc. He did not have his instrument with him, but I had my sitar and he was taking notes from my answers. There came the question of the drone, which is an essential part of our music. I explained that a continuous drone is maintained by the 4 or 5 stringed background drone instrument 'tanpura', which registers mainly the tonic and its fourth or fifth note to establish the 'raga' (or melody form) that the artist is performing. He said that he had been experimenting with the drone effect in some of his compositions after hearing me play, and said that the effect was also very calming and soothing. I had heard, just before meeting him, some cassettes of his latest compositions and I said, "John, if you don't mind I will ask you a question. I just heard some recordings of your new compositions and I was very intrigued" ... he looked perplexed. I continued, "I was so impressed and found it amazing and touching as 
well, but in places I felt you were crying out through your instrument and it was like a shriek of a tormented soul. I have heard the same from many other great jazz performers, which is quite understandable because of their pain and the hurt of generations comes out in their music. But seeing and knowing you I thought that the interest and love of our tradition and music has helped you to overcome this..." I will never forget the expression on his face, and the words which he said with such a deep feeling which brought tears to my eyes. He said, "Ravi, that is exactly what I want to know and learn from you... how you find so much peace in your music and give it to your listeners."

This was in our last meeting - we embraced and parted with such love. We also fixed a future date in the summer of 1967 when he would keep himself free to come to LA for six weeks and take lessons from me. This alas was never to be.

Discovering Coltrane's affinity for Indian music and spirituality inspired in me a deep passion to continue his research here in India. I revere Coltrane's prophetic vision and contributions to creative music, and have found great strength in seeing him through the light of the Guru consciousness. Reaching beyond the superficial contradictions and differences that separate Coltrane's music from raga music, I find common ideals that transcend the limitations of culture and language.

Below are video and audio samples of some of my efforts to reimagine Coltrane's music in different ensembles.

- John Coltrane Indo-Jazz Suite: Living Space, Nature Boy, Afro Blue.

Recorded with my brother Andrew and tabla player Mike Luchis at New York University, November 25th, 2014. This suite of Coltrane repertoire unfolds in the form of a raga: "Living Space" is the alaap (melodic intro), "Nature Boy" is the madhya jhaptaal (medium 5-beat cycle), and "Afro Blue" is the drut (fast tempo).

\section{Click here to listen to audio: John Coltrane Indo-Jazz Suite}

- $\quad$ Prayer and Meditation Suite (John Coltrane), arranged for two saxophones, Indian percussion ensemble, drones and projection.

Recorded live at Indian Council of Cultural Relations, Kolkata, India, 2012. I arranged this Coltrane Suite also in the form of a raga, adapting each composition to follow the alaap, jor (introduction of a slow pulse), madhya gat (medium tempo), and drut gat (fast tempo). This ensemble features some of India's best percussionists: Pandit Gopal Burman, shri khol ${ }^{9}$; Subhajyoti Guha, tabla; and Ratul Shankar, percussion.

Click image below to watch video, "Prayer and Meditation Suite (John Coltrane)":

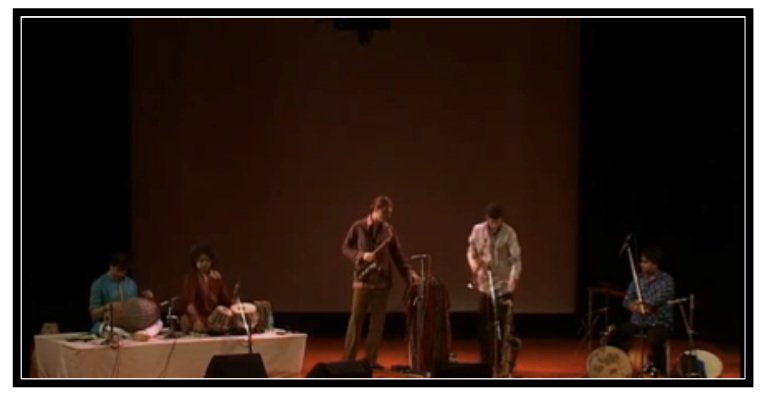

\section{Musical Transcendence}

In the new light of my experiences in India, I can see how building two houses has enriched me as an artist. Even though the traditional Indian house is my focus (I have many years to go before reaching the raga standard I aspire to), I still cultivate my contemporary creative side.

Realizing that my time in India had transformed my fundamental approach to music, I returned home to Toronto in 2014 excited to play with my Indo-Jazz band Kayos Theory (lead by Andrew and I, and featuring Justin Gray on 
double bass and Adam Teixeira and Derek Gray on drums and percussion). We were featured at the Toronto International Jazz Festival with saxophonist Tony Malaby from New York City. Below are two short excerpts from the concert. This experience allowed me to develop a new approach to improvisation, and Tony Malaby (picture right) was a dynamic catalyst.

- "Nature Boy" and "Living Space/India." Recorded by Kayos Theory featuring Tony Malaby live at The Rex Hotel, Toronto International Jazz Festival, June 28, 2014.

Click image below to watch video, "Nature Boy":
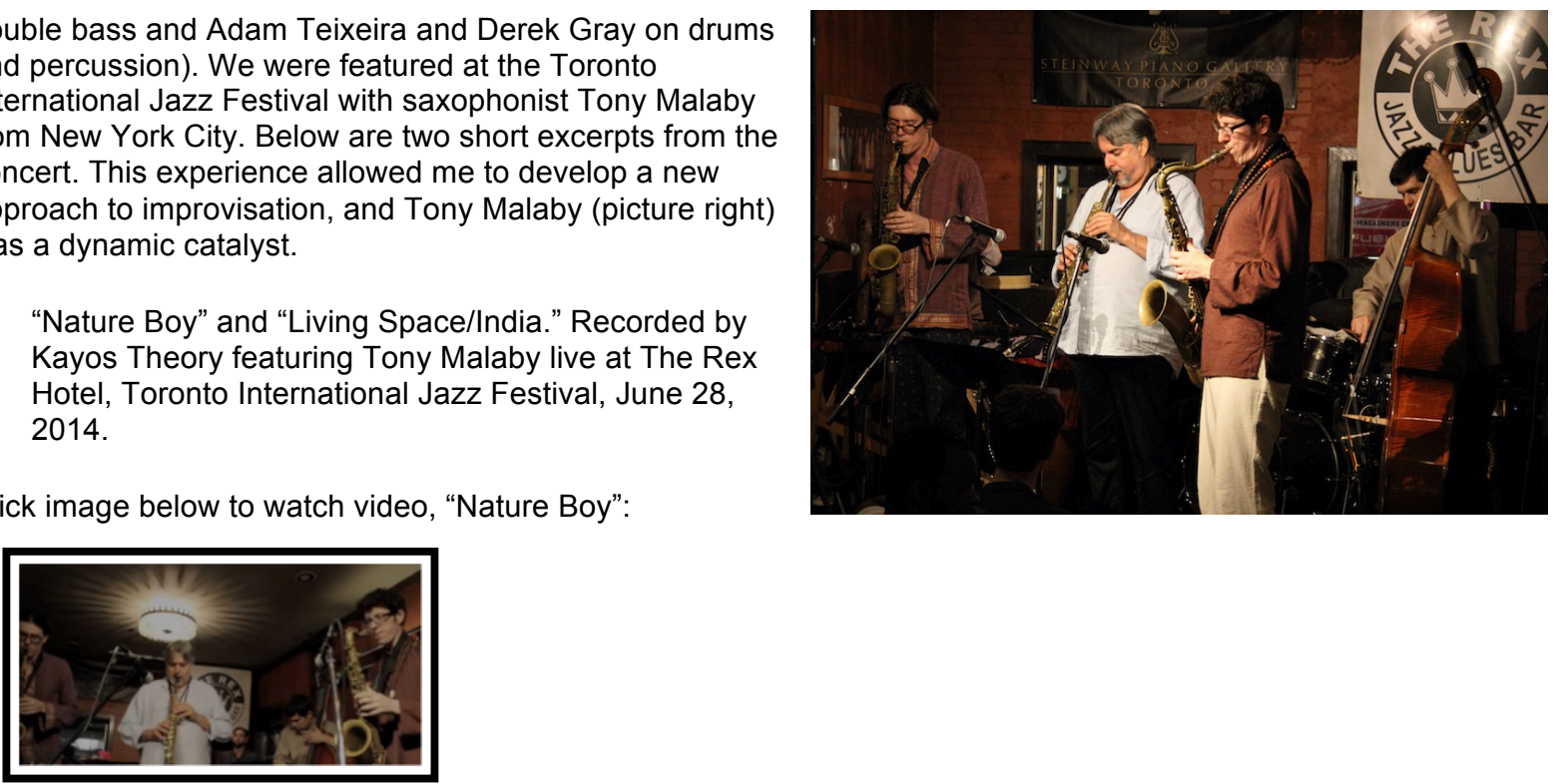

Click image below to watch video, "Living Space/India":

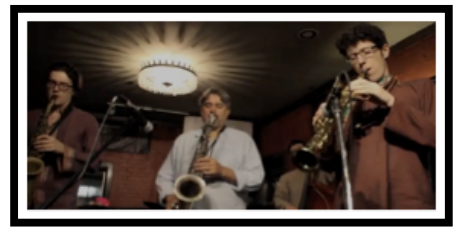

The music of Kayos Theory, which aims to push beyond tradition and genre, lets me use my every experience, musical and otherwise, to inform a personal language. My creative consciousness is free to inspire, motivate, and stimulate musical expression. There is no compartmentalization, or even "mentalization" for that matter: the mind has no role other than as a silent, passive observer. Years of meditation have helped my mind to become a device that merely facilitates the actualization of technical specifics, leading to a cosmic experience, rather than a limited mental creation.

When performing ragas, I still feel the towering walls of tradition, but I know that through time and maturity they can be ascended. I can glimpse the mystical, cosmic platform where Guruji channels the raga consciousness. Contrary to my sense of creative consciousness as vast and impersonal, Guruji tells of a personal, intimate, and yet unlimited energy: "The potency of the raga is infinite", he explained on my first trip. I now realize that Guruji was describing the self-perpetuating nature of the ragas that unfold almost endlessly without becoming repetitive or stagnant. This is much like centre of a circle, a point referred to in Indian philosophy as the bindu: "the individual point which is yet the Universal." (Sri Aurobindo qtd. in Pandit 270). Raga music sadhana has brought stability, clarity, and concentration to my practice, opening me to new states of awareness and musical possibilities.

My experience in both Indian and Western worlds has thus brought me to an integral meeting point of philosophical motive and practical application. Each musical culture and language is a tool to be mastered, informing a holistic lifestyle, which artistically expresses the broadest universal truths. Music is a means of transcendence, an idea first expressed by the ancient Rishis of India (who developed Nad Yoga, the Yoga of music) and later reaffirmed by Coltrane. This meeting point of East and West continues to inspire my creative voice as an improviser and carry me beyond the limitations of language and genre. 


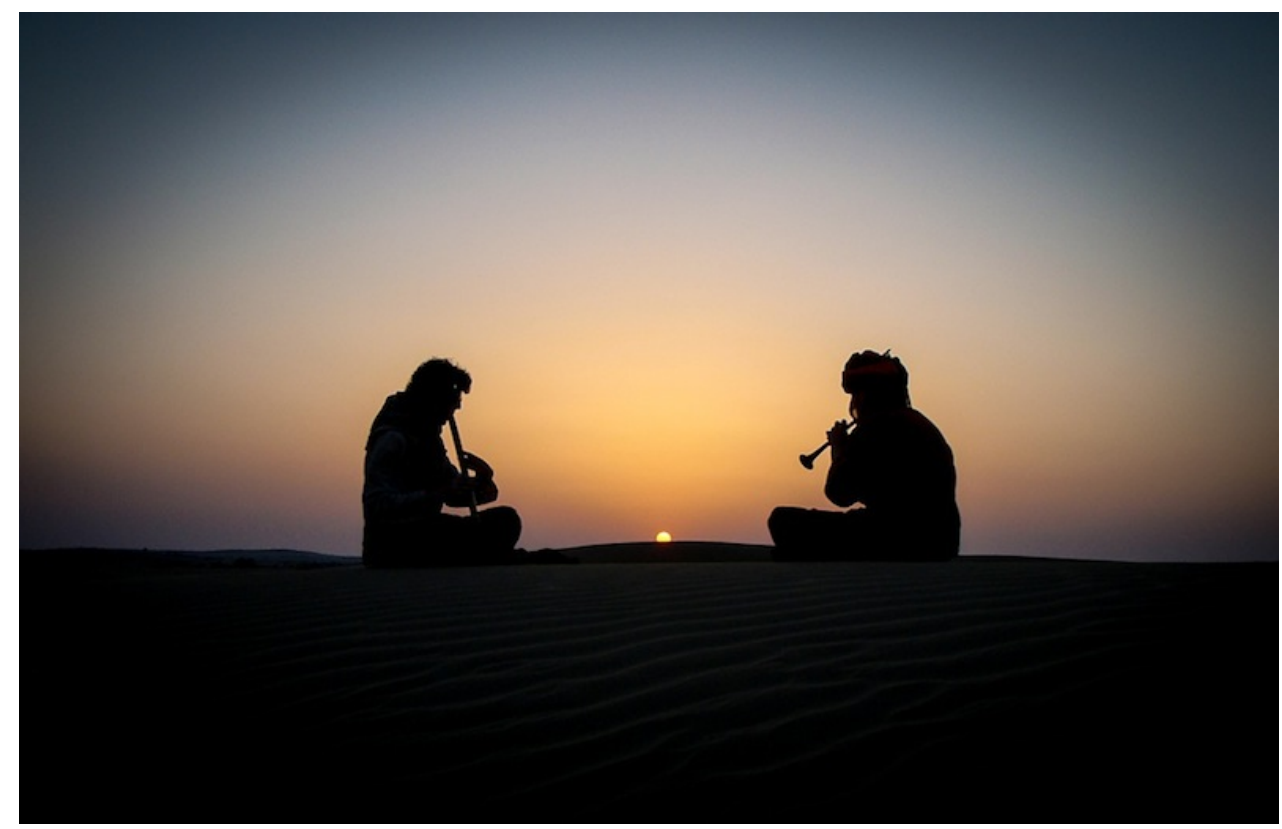

\section{Conclusion}

I first came to India in search of musical inspiration, but I have gained so much more. My journey has involved a cultural migration, living in harmony with the traditional life of my adopted Indian Guru and his family, learning a new language, assimilating Indian philosophy and religion, and embracing a spiritual sadhana.

Musically, I have been trained in vocal dhrupad and khayal music, and I am actively continuing the instrumental traditions of the bansuri and esraj, experience that has informed my development of the Shrutiphone (the first nontempered saxophone) and my pioneering research into its applications in Indian classical music.

Indian classical music has broadened my perspective, helping me understand how music and art can be vehicles to express a greater sense of purpose in life. Through surrendering to the Guru consciousness and the pursuit of Nad Yoga as a new foundation of being, the practice and cultivation of collective improvisation has led me to discover more universal forms of expression, pushing me far beyond my expectations into inspiring new realms of creativity. With experience and maturity, I feel a natural synthesis will harmonically weave all influences together into an integral expression that supports each tradition in which it is rooted. I see now how all artistic and spiritual journeys can follow the same path of transcendence, and I aspire to discover this universal truth in my life and music in order to integrally express who I am.

As a new era of multicultural globalization dawns, I feel I am part of an emerging new evolution of cross-cultural artists who define themselves by searching for universal harmony and truth, in turn giving a deeper significance to the converging of global cultures. As the fragmented modern world desperately searches for meaning and identity, a path of cross-cultural artistic discipline and universal spiritual transcendence may be humanity's best attempt to harmoniously synthesize the fabric of a new world culture. 


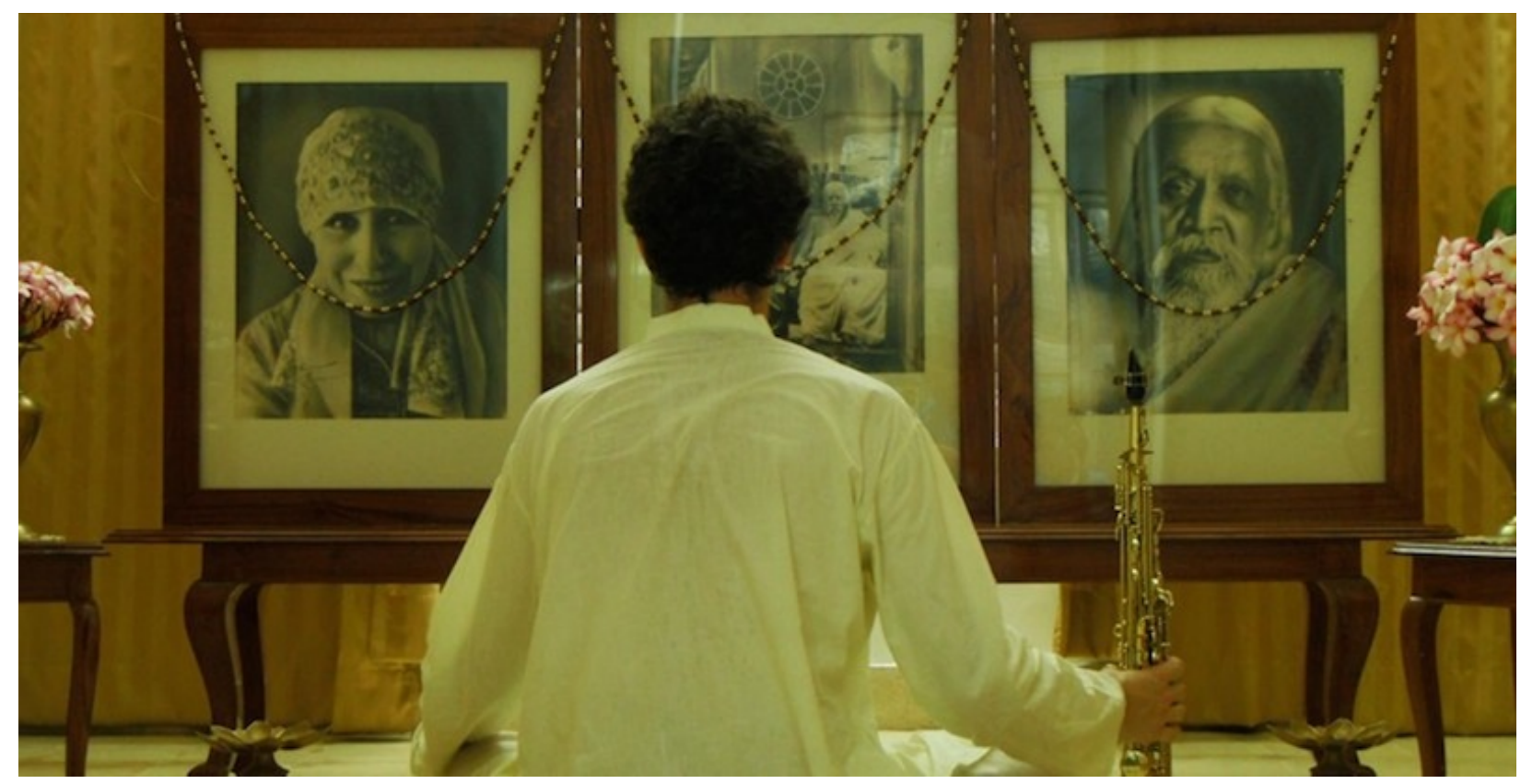

\section{Acknowledgements}

My most sincere Pranaam to my Guruji, Pandit Shantanu Bhattacharyya, and his family. Special thanks to my musical brothers Andrew Kay, Justin Gray, and my wife, Shayna Kay, who have joined me on this wondrous journey in India. Thanks to Amandine Pras for this opportunity to document and share my journey. Thanks to all the musicians featured in the preceding audio and video clips. Photos and videos are courtesy of Andrew Kay, Shayna Kay, Alastair Kay, and Monty Gray. I would like to acknowledge the support of the following organizations that have helped greatly in my journey: Canada Council for the Arts, Ontario Arts Council, Toronto Arts Council, and Shastri Indo-Canadian Fellowship.

\section{Notes}

${ }^{1}$ The tradition of North Indian classical music, also known as Hindustani Raga music.

${ }^{2}$ Note the following definition from the liner notes to Monsoon Trio's album Pranaam: "Born from the spiritual revelations of India's Rishis and Yogis, the Ragas are musical entities experienced as states of vibrational consciousness. Expressed as intricate melodies in ever changing layas (tempos), they create specific moods that harmonise with the unending interplay between Nature's cycles and Life's emotions. The artist develops a relation to the Raga within oneself and identifies their life's movements through this music."

${ }^{3}$ A custom made fretless bass with added drone strings (chikaree) and harp (tarrif). Invented and co-created by Justin Gray with luthier Les Godfrey.

${ }^{4}$ A title used to describe the highest level of maestro musicians.

${ }^{5}$ I will subsequently attach the traditional Hindi honorific "ji" to given names.

${ }^{6}$ There are twenty-three official languages in India, including English, and most Indians are multilingual in three or four related languages. The "mother tongue" is the regional language one grew up speaking.

${ }^{7}$ Please visit this link to read a short article on John Coltrane's spirituality: http://www.monsoonmusic.com/Looking_East.html. 
${ }^{8}$ One who practices the esoteric teachings of the tantric path in Hinduism. Realization in the tantric path comes by entering into union with the Hindu gods through ritualistic offerings and ceremonies.

${ }^{9}$ A double-sided clay drum from Bengal. Used traditionally to play kirtan, a semi-classical form of folk music.

\section{Works Cited}

Alfassa, Mira. Words of The Mother II. Pondicherry, India: Sri Aurobindo Ashram Press, 1980. Print.

Baham III, Nicholas Louis. The Coltrane Church: Apostles of Sound, Agents of Social Justice. Jefferson, North Carolina: McFarland \& Company, Inc., Publishers, 2015. Print.

Berkman, Franya. "Appropriating Universality: The Coltranes and 1960s Spirituality." American Studies 48 (2007): 4162. Print.

Chaurasia, Pandit Hariprasad. Interview by Kavita Chhibber. Kavita Chhibber. Kavita Media, n.d. Web. 12 Jan. 2016.

DeVito, Chris. Coltrane on Coltrane: The John Coltrane Interviews. Chicago: Chicago Review Press, 2012. Print.

Hentoff, Nat. Liner Notes. Live at the Village Vanguard. By John Coltrane. Impulse, 1962. CD.

Monsoon Trio. Liner Notes. Pranaam. TheJazzBox.ca, 2015. CD.

Pandit, M.P. Dictionary of Sri Aurobindo's Yoga. Twin Lakes, WI: Lotus Light, 1992. Print.

Shankar, Ravi. "Reminiscences about John Coltrane, 2001." The Ravi Shankar Foundation. The Ravi Shankar Foundation, 11 July 2013. Web. 12 Jan. 2016. 